\title{
Letter \\ Outcome research in meningococcal septic shock
}

\author{
Corinne Buysse ${ }^{1}$, Lindy Vermunt ${ }^{2}$, Elisabeth Utens ${ }^{2}$, Koen Joosten ${ }^{1}$ and Jan Hazelzet ${ }^{1}$
}

\begin{abstract}
${ }^{1}$ Erasmus MC-Sophia Children's Hospital, Department of Paediatrics, Division of Paediatric Intensive Care, Rotterdam, the Netherlands 2Erasmus MC-Sophia Children's Hospital, Department of Child and Adolescent Psychiatry, Rotterdam, the Netherlands
\end{abstract}

Corresponding author: Corinne Buysse, c.buysse@erasmusmc.nl

Published: 17 January 2008

This article is online at http://ccforum.com/content/12/1/402

(c) 2008 BioMed Central Ltd

Critical Care 2008, 12:402 (doi:10.1186/cc6206)

See related commentary by Paize and Playfor, http://ccforum.com/content/11/5/172

and related research by Maat et al., http://ccforum.com/content/11/5/R112

We thank Dr Paize and Dr Playfor for their comments [1] regarding our earlier article in Critical Care [2].

In their commentary Dr Paize and Dr Playfor stated that the reasons for a marked reduction in the mortality of children with meningococcal disease in the paediatric intensive care unit are multifactorial: increased centralization of the paediatric intensive care unit, improvement in awareness, clinical guidelines for children with sepsis, and incorporation of meningococcal serogroup $\mathrm{C}$ vaccine.

Dr Paize and Dr Playfor also regretted in their commentary that we did not examine morbidity in our large cohort [1]. We completely agree with $\mathrm{Dr}$ Paize and Dr Playfor that both short-term and long-term outcomes in survivors of meningococcal sepsis are clinically highly relevant. Only a few, unsystematic studies have been conducted in this field. These studies used small, heterogeneous patient samples and unstandardized assessment procedures and were focused mainly on short-term outcome. Our relatively large, homogeneous cohort therefore offered the possibility to investigate this neglected area of outcome, both from a medical and psychosocial point of view, with standardized procedures. Parts of our outcome study have been published already or are in press [3-6].

In a prospective cohort study we performed a short-term follow-up of all consecutive children with septic shock and purpura requiring intensive care treatment between 2001 and 2005, and their parents [4]. Up to 2 years after paediatric intensive care unit discharge, chronic complaints were reported in nearly one-half of the children. Significantly lower scores were found on health-related quality-of-life scales concerning mainly physical functioning and health perception in comparison with normative data. Quite a few mothers suffered from anxiety or depression requiring professional help.
The second part of our study concerned a cross-sectional long-term outcome study of all 179 survivors of septic shock and purpura requiring intensive care treatment between 1988 and 2001, and their parents [3,5,6]. Regarding long-term health-related quality of life, we found significantly lower scores in patients - mainly on physical domains (physical functioning, general health perception) - compared with Dutch normative data [3]. Adolescents (aged 12-17 years) who survived meningococcal septic shock in childhood, especially those with skin scarring due to purpura, reported lower self-esteem compared with reference adolescents [5]. Overall, we found favourable long-term behavioural, emotional and post-traumatic stress outcomes in patients [6].

Articles regarding skin scarring, orthopaedic and neurological sequelae, as well as psychosocial adjustment of parents, are under review.

In conclusion, we would like to reassure Dr Paize and Dr Playfor that we did study short-term and long-term morbidity in survivors of septic shock and purpura.

\section{Competing interests}

The authors declare that they have no competing interests.

\section{References}

1. Paize F, Playfor SD: Improvements in the outcome of children with meningococcal disease [commentary]. Crit Care 2007, 11:172.

2. Maat M, Buysse CM, Emonts M, Spanjaard L, Joosten KF, Groot $\mathrm{RD}$, Hazelzet JA: Improved survival of children with sepsis and purpura: effects of age, gender, and era. Crit Care 2007, 11: R112.

3. Buysse CM, Raat $\mathrm{H}$, Hazelzet JA, Vermunt LC, Utens EM, Hop WC, Joosten KF: Long-term health-related quality of life in survivors of meningococcal septic shock in childhood and their parents. Qual Life Res 2007, 16:1567-1576.

4. Buysse CMP, Raat H, Hazelzet JA, Hop WCJ, Maliepaard M, Joosten KFM: Surviving meningococcal septic shock: health consequences and quality of life in children and their parents up to 2 years after PICU discharge. Crit Care Med 2008, in press. 
5. Vermunt LC, Buysse CMP, Joosten KFM, Oranje AP, Hazelzet JA, Verhulst FC, Utens EM: Self-esteem in children and adolescents after septic shock caused by Neisseria meningitidis: scars do matter. $J$ Adolesc Health 2008 , in press.

6. Vermunt LCAC, Buysse CMP, Joosten KFM, Hazelzet JA, Verhulst FC, Utens EM: Behavioral, emotional and post-traumatic stress problems in children and adolescents long-term after septic shock caused by Neisseria meningitidis. $\mathrm{Br} J$ Clin Psychology 2007, 24:[Epub ahead of print]. 